\title{
Gas and crystal structures of $\mathrm{CCl}_{2} \mathrm{FSCN}^{\text {is }}$
}

\author{
Yanina Berrueta Martínez a, Lucas S. Rodríguez Pirani a , Mauricio F. Erben ${ }^{a}$, \\ Roland Boese ${ }^{c}$, Christian G. Reuter ${ }^{b}$, Yury V. Vishnevskiy ${ }^{b}$, Norbert W. Mitzel ${ }^{\text {b, }}{ }^{* *}$, \\ Carlos O. Della Védova ${ }^{\text {a, * }}$ \\ a CEQUINOR (UNLP-CONICET), Departamento de Química, Facultad de Ciencias Exactas, Universidad Nacional de La Plata, 47 esq. 115, 1900 La Plata, \\ Argentina \\ ${ }^{\mathrm{b}}$ Lehrstuhl für Anorganische Chemie und Strukturchemie, Universität Bielefeld, Universitätsstraße 25, 33615 Bielefeld, Germany \\ c Strukturchemie-Institut für Anorganische Chemie, Universität Duisburg Essen, Universitätsstraße 7, 45117 Essen, Germany
}

\section{A R T I C L E I N F O}

Article history:

Received 25 January 2016

Received in revised form

25 March 2016

Accepted 28 March 2016

Available online 30 March 2016

Keywords:

Dichlorofluoromethyl thiocyanate

Gas electron diffraction

X-ray diffraction

\begin{abstract}
A B S T R A C T
Dichlorofluoromethyl thiocyanate, $\mathrm{CCl}_{2} \mathrm{FSCN}$, was structurally studied in the solid and in the gas phase by means of single-crystal X-ray (XRD) and gas electron diffraction (GED), respectively. In the gas phase the title molecule adopts two stable conformers, described by the FC-SC dihedral angle. The gaucheconformer (FC bond with respect to the SC bond) is more stable than the anti-conformer. In this work we present the first experimental evidence for the existence of the anti- $\mathrm{CF}_{2} \mathrm{ClSCN}$ form. In the solid state only the most stable gauche-conformer was found. Intermolecular interactions were detected in the crystal structure and analyzed. A structural comparison of the results with those of related species as $\mathrm{CCl}_{2} \mathrm{FSCN}, \mathrm{CCl}_{3} \mathrm{SCN}$ and $\mathrm{CH}_{2} \mathrm{ClSCN}$ is presented.
\end{abstract}

(c) 2016 Elsevier B.V. All rights reserved.

\section{Introduction}

The family of thiocyanate compounds is under permanent investigation. Some experimental IR and Raman spectroscopy data as well as theoretical investigations for this species have been reported twenty years ago by our group [1]. In this work, gauche$\mathrm{CCl}_{2} \mathrm{FSCN}$ was experimentally detected by means of Raman polarization measurements supplemented by computational chemistry calculations. On the other hand, the anti-conformer could only be computed by quantum-chemical calculations. Experimental support for the less stable anti-conformer is now finally provided by the gas phase electron diffraction study presented in this work. Complementarily, X-ray diffraction measurements allow determining the crystal structure of the less symmetric and more abundant gauche-conformer. Some intermolecular interactions in terms of geometrical parameters involving halogen and chalcogen atoms have been determined. Finally, a comparison of the gas and crystal-phase structures between $\mathrm{CCl}_{2} \mathrm{FSCN}, \mathrm{CCl}_{3} \mathrm{SCN}$ [2] and

\footnotetext{
Dedicated to Prof. Dr. Georgiy Vasil'evich Girichev on occasion of his $70^{\text {th }}$ anniversary on January 13, 2017.

* Corresponding author.

** Corresponding author.

E-mail address: carlosdv@quimica.unlp.edu.ar (C.O. Della Védova).
}

$\mathrm{CH}_{2} \mathrm{ClSCN}[3]$ is presented.

\section{Experimental section}

\subsection{Synthesis}

$\mathrm{CCl}_{2} \mathrm{FSCN}$ was prepared by the reaction of $\mathrm{CCl}_{2} \mathrm{FSCl}$ with $\mathrm{KCN}$ in ether [4]. Purification was performed by several trap-to-trap distillations [5]. The identity and purity of dichlorofluoromethyl thiocyanate were verified using infrared spectroscopy.

\subsection{Instrumentation and procedure}

\subsubsection{Quantum-chemical calculations}

The Gaussian 03 suite of programs [6] was used to compute DFT [7] and MP2 [8] calculations. The existence of minima on the potential hyper-surface was proved computing the corresponding harmonic frequencies after each geometry optimization. For the GED structural analyses analytical harmonic and numeric cubic force fields were calculated at the B3LYP/6-31G(d) and O3LYP/ccpVTZ levels of the theory. These results were then used to calculate mean-square interatomic vibrational amplitudes and vibrational corrections to the equilibrium structure by the SHRINK program [9-11]. Coupled-cluster CCSD and $\operatorname{CCSD(T)~[12]~analytical~}$ 
gradient-powered geometry optimizations were performed using the Cfour program package [13].

In order to search the nature of the halogen or chalcogen intermolecular interactions, NBO computational calculations were performed by means of the NBO package contained in the Gaussian 03 program [14]. The second-order perturbation stabilization energies $(E)$ associated to the charge transfer between electron donor and acceptor orbitals corresponding to adjacent molecules were calculated at the NBO B3LYP/6-311 + G(d) level of approximation.

\subsubsection{Gas electron diffraction}

Gas electron diffraction patterns were measured using the improved Balzers Eldigraph KD-G2 gas-phase electron diffractometer [15] at Bielefeld University. The experimental details are depicted in Table S1. Diffraction images were measured on the Fuji BAS-IP MP2 2025 imaging plates, which subsequently were scanned using the calibrated Fuji BAS-1800II scanner. The intensity curves (see Fig. S1 - S2) were retrieved from the scanned diffraction images by applying the method described earlier [16]. Sector functions and electron wavelengths were calibrated as usually using benzene diffraction patterns, recorded along with the substance under investigation [17]. Experimental amplitudes were refined in groups (see Tables S1 - S2). For this purpose scale factors (one per group) were used as independent parameters. The ratios between different amplitudes in one group were fixed at the theoretical values.

Two sets of theoretical amplitudes and corrections, calculated from B3LYP/6-31G(d) and O3LYP/cc-pVTZ force fields, were tested in the refinements. Those calculated at the B3LYP/6-31G(d) level allowed obtaining better agreement with experimental data and were used in the final models. For $\mathrm{CCl}_{2} \mathrm{FSCN}$, three GED models were used: (a) anti-conformation, (b) gauche-conformation and (c) a mixture of both conformations. The largest correlations (more than 0.7) obtained were: $r(\mathrm{C} 1-\mathrm{S} 2) / l 1=0.82, r(\mathrm{C} 1-\mathrm{S} 2) /$ $r(\mathrm{C} 1-\mathrm{Cl} 6)=-0.74,<(\mathrm{S} 2-\mathrm{C} 1-\mathrm{F} 5) / \chi=-0.73, r(\mathrm{~S} 2-\mathrm{C} 3) / \chi=-0.73$. The definitions for groups of refined amplitudes are given in Tables S2 and S3.

\subsubsection{X-ray diffraction}

Crystallography measurements were carried out at EssenDuisburg University. A four circle Nicolet $\mathrm{R} 3 \mathrm{~m} / \mathrm{V}$ diffractometer, with a Mo-K $\alpha$ source $(\lambda=0.71073 \AA$ ) was used [18]. Crystal structures were solved by the Patterson method and refined with SHELXTL-Plus Version SGI IRIS indigo Software [19]. The sample was placed in a $0.2-0.3 \mathrm{~mm}$ diameter glass capillary, which was closed at both ends. Using a coupled microscope integrated to the diffractometer, the formation of microcrystals (polycrystalline) was observed while decreasing the temperature of the sample. The sample was cooled at about $15 \mathrm{C}$ below the melting point, and, with a melting zone by zone procedure and subsequent recrystallization caused by heating with an infrared laser focused to a very small area of the sample, a single crystal suitable for an X-ray diffraction experiment grew. A detailed description of this technique is reported in the literature [20]. Table 1 lists the parameters of the XRD experiments.

CCDC 1021027 contains the supplementary crystallographic data for this paper. These data can be obtained free of charge from The Cambridge Crystallographic Data Centre via www.ccdc.cam.ac. uk/data_request/cif.

\section{Results and discussion}

\subsection{Computational chemistry}

The structure of dichlorofluoromethyl thiocyanate (Fig. 1) was
Table 1

Details of the X-ray diffraction experiments for $\mathrm{CCl}_{2} \mathrm{FSCN}$.

\begin{tabular}{|c|c|}
\hline Chemical formula & $\mathrm{CCl}_{2} \mathrm{FSCN}$ \\
\hline$M_{\mathrm{r}}$ & 160.0 \\
\hline Unit cell, space group & orthorhombic, $P 2_{1} 2_{1} 2_{1}$ \\
\hline Temperature $(\mathrm{K})$ & $193(1)$ \\
\hline$a(\AA)$ & $5.9327(1)$ \\
\hline$b(\AA)$ & $8.38740(2)$ \\
\hline$c(\AA)$ & $11.5697(1)$ \\
\hline$\beta\left({ }^{\circ}\right)$ & 90 \\
\hline$V\left(\AA^{3}\right)$ & $575.707(13)$ \\
\hline$Z$ & 4 \\
\hline$\rho_{\text {calc }}$ (calculated) $\left(\mathrm{g} \mathrm{cm}^{-3}\right)$ & 1.8454 \\
\hline$F(000)$ & 312 \\
\hline Crystal color & Colorless \\
\hline Crystal description & Cylindrical \\
\hline Wavelength $(\AA)$ & 0.71073 \\
\hline$\mu\left(\mathrm{mm}^{-1}\right)$ & 1.38 \\
\hline Crystal size $(\mathrm{mm})$ & 0.3 \\
\hline$\theta$ range & $3.00^{\circ}-30.47^{\circ}$ \\
\hline Completeness to $\theta_{\max }$ & $84.7 \%$ \\
\hline Index range $h, k, l$ & $-8 / 8,-9 / 9,-16 / 16$ \\
\hline Transm.max/min & $0.75 / 0.70$ \\
\hline$R$ before/after correct & $0.0746 / 0.0300$ \\
\hline Collected reflections & 6628 \\
\hline Independent reflections & 1503 \\
\hline$R($ int $)$ & 0.019 \\
\hline Data/restraints/parameters & $1461 / 0 / 65$ \\
\hline Goodness of fit in $F^{2}$ & 1.033 \\
\hline$R 1 / \mathrm{w} R 2$ [observed refl.] & $0.0225 / 0.0558$ \\
\hline Observed refl. with & $I>2 \sigma(I)$ \\
\hline$R 1 / \mathrm{wR} 2$ (complete data) & $0.0234 / 0.0566$ \\
\hline Extinction coefficient & $0.005(3)$ \\
\hline$\rho_{\max / \min }\left(e \AA^{-3}\right)$ & $0.32 /-0.31$ \\
\hline CCDC no. & 1020624 \\
\hline
\end{tabular}

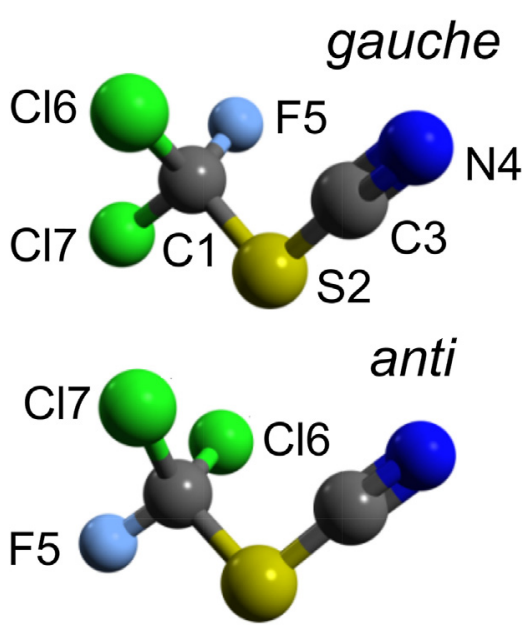

Fig. 1. Molecular structure and atom numbering scheme of the gauche- and anticonformers of $\mathrm{CCl}_{2} \mathrm{FSCN}$.

quantum-chemically computed using B3LYP/cc-pVTZ and MP2/ccpVTZ levels of approximations. The potential-energy functions against the internal rotation around the $\varphi(\mathrm{F}-\mathrm{C}-\mathrm{S}-\mathrm{C})$ dihedral angle is shown in Fig. 2. As can be seen from Fig. 2, the gaucheconformation with a $\varphi(\mathrm{FC}-\mathrm{CS})$ dihedral angle around $60^{\circ}$ is more stable than the anti-form, with a $\varphi(\mathrm{F}-\mathrm{C}-\mathrm{C}-\mathrm{S})$ dihedral angle near $180^{\circ}$. Maxima in the potential energy curves are observed for structures with eclipsed orientation between the halogens of $\mathrm{CCl}_{2} \mathrm{~F}$ and the $\mathrm{CN}$ group of thiocyanate SCN.

Despite the qualitative agreement within both methods, the B3LYP level, predicts lower energy barriers than the MP2 method 


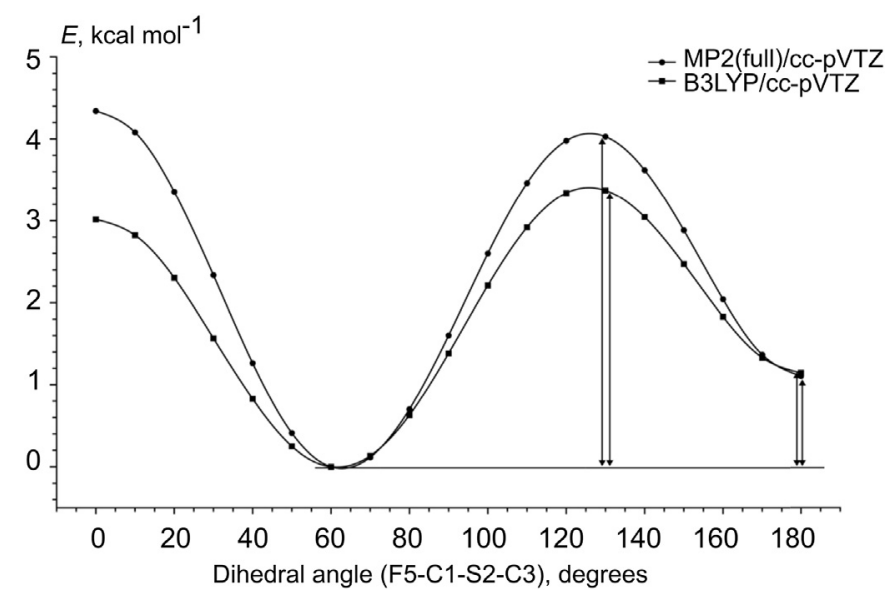

Fig. 2. Potential energy functions of the internal rotation around the $\varphi(F-C-S-C)$ dihedral angle of $\mathrm{CCl}_{2} \mathrm{FSCN}$.

[21].

The rotational barrier computed for the gauche $\rightarrow$ anti conversion in $\mathrm{CCl}_{2} \mathrm{FSCN}$ with the mentioned approximation levels agrees with the computed with $\mathrm{HF} / 3-21 \mathrm{G}^{*}, \mathrm{HF} / 6-31 \mathrm{G}^{*}$ and $\mathrm{MP} 2 / 6-31 \mathrm{G}^{*}$ [1]. Moreover, it is very similar to that obtained in $\mathrm{CCl}_{3} \mathrm{SCN}$ [2] and more than twice than the corresponding barrier in $\mathrm{CH}_{2} \mathrm{ClSCN}$ [3].

The structures of the two minima were then fully optimized and their frequencies were computed at the same levels of theory. Table 2 lists the relative energies $(\Delta E)$ and Gibbs free energies $\left(\Delta G^{0}\right)$ along with the conformational population, which was calculated using the Boltzmann distribution taking into account the degeneration of the gauche-conformer. The concentration of the anticonformation in $\mathrm{CCl}_{2} \mathrm{FSCN}$ (ca. $7 \%$ ) is about a half than the concentration of an anti-rotamer in $\mathrm{CH}_{2} \mathrm{ClSCN}$ (between 15 and 18\%) [3].

Furthermore, we also applied the most accurate $\operatorname{CCSD}(\mathrm{T})$ method to the $\mathrm{CCl}_{2} \mathrm{FSCN}$ molecule in order to compute theoretical structures for comparison with the experimental data (see Table 3).

\subsection{Molecular structures}

The most relevant structural parameters of $\mathrm{CCl}_{2} \mathrm{FSCN}$ are given in Table 3.

\subsection{Molecular structure in the gas phase}

An experimental determination of the gas-phase structure of $\mathrm{CCl}_{2} \mathrm{FSCN}$ was determined by means of gas electron diffraction (GED). Relevant geometric parameters obtained by GED, solid state $\mathrm{X}$-ray diffraction (XRD) and computational calculations are listed together in Table 3 for comparison. Different theoretical models (100\% gauche, $100 \%$ anti and a mixture of both conformers) were used in the refining process of $\mathrm{CCl}_{2} \mathrm{FSCN}$. The radial distribution

Table 2

Relative total $\Delta E$ and free Gibbs $\Delta G$ energies $\left(\mathrm{kcal} \mathrm{mol}^{-1}\right)$ and abundancies $\chi(\%)$ of anti-conformer of $\mathrm{CCl}_{2} \mathrm{FSCN}$.

\begin{tabular}{llll}
\hline & $\Delta E^{\mathrm{a}}$ & $\Delta G^{\mathrm{a}}$ & $\chi^{\mathrm{a}}$ \\
\hline B3LYP/cc-pVTZ & 1.15 & 1.12 & 7.3 \\
MP2(full)/cc-pVTZ & 1.13 & 1.11 & 7.4 \\
\hline
\end{tabular}

${ }^{a}$ Energies are relative to those of gauche conformers. Gibbs free energies were calculated using standard "uncoupled harmonic rotator - rigid oscillator" approximation. The abundance was calculated from a free Gibbs energy at $305 \mathrm{~K}$. function as well as the corresponding structural $R$-factors obtained applying the different models are given in Fig. 3.

Even though the gauche-conformer is by far the most abundant, molecules with anti-conformation were also detected in the gas phase at the 300 and $315 \mathrm{~K}$ (detailed in Table S1). A straightforward estimation of the conformational composition from the radial distribution function is rather difficult in the present case. The N4-F5 contribution of the anti-conformer at $r=4.8 \AA$ is not as conclusive as in the refining of the equivalent $\mathrm{Cl}-\mathrm{N}$ contribution in the $\mathrm{CH}_{2} \mathrm{ClSCN}$ molecule [3]. The present contribution is difficult to observe not only due to the neighboring broad $\mathrm{N} 4-\mathrm{Cl} 7$ contribution of the gauche-conformer but also due to experimental noise (see Fig. 3). On the other hand, all other interatomic distances are similar for the gauche- and anti-rotamers. Consequently, the value of the least-squares functional in the structural analysis is not sensitive (see Fig. S3) to the changes in conformational composition of $\mathrm{CCl}_{2} \mathrm{FSCN}$. Additional difficulties in the refinement of the conformations ratio arise due to significant correlations as described in the experimental section. The finally refined ratio between gauche and anti-conformers of $\mathrm{CCl}_{2} \mathrm{FSCN}$ in the gas phase at $305 \mathrm{~K}$ was 79(11):21(11)\%, respectively. The above described experimental results are generally in agreement with the computed values assuming the limited predicting power of the used approximations. Relevant geometric parameters obtained with XRD, GED and theoretical calculations (CCSD(T)/cc-pVTZ) are compared in Table 3.

Table 4 lists a comparison of the geometrical parameters of $\mathrm{CH}_{2} \mathrm{ClSCN}, \mathrm{CCl}_{3} \mathrm{SCN}$ and $\mathrm{CCl}_{2} \mathrm{FSCN}$. According to our previous work, simple thiocyanates $\mathrm{CH}_{2} \mathrm{ClSCN}, \mathrm{CCl}_{3} \mathrm{SCN}$ and $\mathrm{CCl}_{2} \mathrm{FSCN}$ present similar $\mathrm{C} \equiv \mathrm{N}$ bond lengths in the gas phase [2,3]. Moreover, this parameter is rather independent on the conformation. The differences between the $\mathrm{C}-\mathrm{Cl}$ bond lengths in this series of compounds are not significant. The longest $\mathrm{C} 1-\mathrm{S} 2$ bonds were observed in $\mathrm{CCl}_{3} \mathrm{SCN}\left(r_{\mathrm{g}}=1.839(2) \AA\right)$ and anti-CCl ${ }_{2} \mathrm{FSCN}\left(r_{\mathrm{g}}=1.839(13) \AA\right)$; this can be explained by steric repulsions of the $\mathrm{CCl}_{3}$ or $\mathrm{CCl}_{2} \mathrm{~F}$ with the $\mathrm{SCN}$ group. The gauche-conformer of $\mathrm{CH}_{2} \mathrm{ClSCN}$ presents the shortest $\mathrm{C} 1-\mathrm{S} 2$ bond. This parameter was found to be dependent on the orientation of the $\mathrm{C}-\mathrm{Cl}$ bond with respect to the $\mathrm{S} 2-\mathrm{C} 3$ bond; acquiring a higher value for the anti-conformation. This is also the case for the $\mathrm{CCl}_{3} \mathrm{SCN}$ molecule (see Table 4).

\subsection{Molecular structure in the solid state and intermolecular contacts}

\subsubsection{Crystal structure of $\mathrm{CCl}_{2} \mathrm{FSCN}$}

$\mathrm{CCl}_{2} \mathrm{FSCN}$ crystallizes in the orthorhombic space group $P 2{ }_{1} 2_{1} 2_{1}$, and contains four molecules in the unit cell. The molecules in the crystal adopt the gauche-conformation with a dihedral angle $\delta(\mathrm{F}-\mathrm{C}-\mathrm{S}-\mathrm{C})$ of $61.5(4)^{\circ}$ (Fig. 4). The computed dihedral angle $\left(62.0^{\circ}\right)$ also reproduces the crystallographic value.

The most important intermolecular interactions observed in the crystal phase are represented in Fig. 5 and listed in Table 5. Two non-bonding interaction types, N...S (Fig. 5, part b) and $\mathrm{N} \cdots \mathrm{Cl}$ (part c), determine the arrangement of the title species in the crystal. The $\mathrm{N}$...S contact of $3.19 \AA$ A is considerably shorter than the sum of the van der Waals radii of the involved atoms ( $3.35 \AA$ ). The experimental value of the $\mathrm{N} \cdots \mathrm{S}-\mathrm{C}$ angle of $159^{\circ}$ together with the results of the NBO calculations computing an interaction between the nitrogen lone pair (as an electron donor) and the $\sigma^{*}(\mathrm{~S}-\mathrm{C})$ molecular orbital (as an electron acceptor) allowed us classifying this contact as a chalcogen intermolecular interaction being the $\sigma^{*}(\mathrm{~S}-\mathrm{C})$ the so-called " $\sigma$-hole" [22]. On the other side, the intermolecular contact between nitrogen and chlorine atoms is responsible for the formation of zigzag head-to-tail $\mathrm{CCl}_{2} \mathrm{FSCN}$ chains. Adjacent chains are alternately joined through two equivalent $\mathrm{N} \cdot \mathrm{SS}$ chalcogen-bond type interactions. The slight 
Table 3

Experimental and theoretical structural parameters of $\mathrm{CCl}_{2} \mathrm{FSCN}$.

\begin{tabular}{|c|c|c|c|c|c|c|c|}
\hline & \multicolumn{4}{|l|}{ gauche } & \multicolumn{3}{|l|}{ anti } \\
\hline & \multicolumn{2}{|l|}{ GED } & \multirow{2}{*}{$\frac{\mathrm{XRD}}{r_{\alpha}^{\mathrm{g}}}$} & \multirow{2}{*}{$\frac{\operatorname{CCSD}(\mathrm{T})}{r_{\mathrm{e}}}$} & \multicolumn{2}{|l|}{ GED } & \multirow{2}{*}{$\frac{\operatorname{CCSD}(\mathrm{T})}{r_{\mathrm{e}}}$} \\
\hline & $r_{\mathrm{e}}^{\mathrm{e}}$ & $r_{\mathrm{g}}^{\mathrm{f}}$ & & & $r_{\mathrm{e}}$ & $r_{\mathrm{g}}$ & \\
\hline $\mathrm{C} 1-\mathrm{S} 2$ & $1.815(13)^{1}$ & $1.828(13)$ & $1.822(5)$ & 1.833 & $1.825(13)^{1}$ & $1.839(13)$ & 1.844 \\
\hline $\mathrm{S} 2-\mathrm{C} 3$ & $1.684(8)^{2}$ & $1.690(8)$ & $1.698(6)$ & 1.700 & $1.678(8)^{2}$ & $1.685(8)$ & 1.695 \\
\hline $\mathrm{C} 3-\mathrm{N} 4$ & $1.160(5)^{3}$ & $1.165(5)$ & $1.144(9)$ & 1.164 & $1.161(5)^{3}$ & $1.165(5)$ & 1.164 \\
\hline $\mathrm{C} 1-\mathrm{F} 5$ & $1.338(5)^{4}$ & $1.345(5)$ & $1.341(6)$ & 1.338 & $1.345(5)^{4}$ & $1.352(5)$ & 1.345 \\
\hline $\mathrm{C} 1-\mathrm{Cl} 6$ & $1.754(4)^{5}$ & $1.761(4)$ & $1.750(4)$ & 1.762 & $1.754(4)^{5}$ & $1.762(4)$ & 1.762 \\
\hline $\mathrm{C} 1-\mathrm{Cl} 7$ & $1.761(4)^{5}$ & $1.770(4)$ & $1.754(4)$ & 1.769 & $1.754(4)^{5}$ & $1.762(4)$ & 1.762 \\
\hline $\mathrm{C} 1-\mathrm{S} 2-\mathrm{C} 3$ & $96.5(13)^{6}$ & & $97.5(2)$ & 97.6 & $97.0(13)^{6}$ & & 98.1 \\
\hline $\mathrm{S} 2-\mathrm{C} 3-\mathrm{N} 4$ & $177.1^{\mathrm{b}}$ & & $177.8(5)$ & 177.1 & $177.1^{\mathrm{b}}$ & & 177.1 \\
\hline $\mathrm{S} 2-\mathrm{C} 1-\mathrm{F} 5$ & $110.6(3)^{7}$ & & $110.9(3)$ & 110.4 & $103.3(3)^{7}$ & & 103.2 \\
\hline $\mathrm{S} 2-\mathrm{C} 1-\mathrm{Cl} 6$ & $112.0(10)^{8}$ & & 113.1(3) & 112.9 & $111.4(10)^{8}$ & & 112.3 \\
\hline $\mathrm{S} 2-\mathrm{C} 1-\mathrm{Cl} 7$ & $107.2(24)^{9}$ & & $104.9(3)$ & 104.6 & $111.4(10)^{8}$ & & 112.3 \\
\hline $\mathrm{F} 5-\mathrm{C} 1-\mathrm{Cl} 6$ & $108.5(3)^{7}$ & & $107.8(4)$ & 108.4 & $109.3(3)^{7}$ & & 109.1 \\
\hline $\mathrm{F} 5-\mathrm{C} 1-\mathrm{Cl} 7$ & $109.4(3)^{7}$ & & $109.2(4)$ & 109.3 & $109.3(3)^{7}$ & & 109.1 \\
\hline $\mathrm{Cl} 6-\mathrm{C} 1-\mathrm{Cl} 7$ & $109.0(28)^{c}$ & & $111.0(2)$ & 111.2 & $111.7(20)^{\mathrm{c}}$ & & 110.5 \\
\hline $\mathrm{F} 5-\mathrm{C} 1-\mathrm{S} 2-\mathrm{C} 3$ & $57.3(41)^{10}$ & & $61.5(4)$ & 62.0 & $180.0^{\mathrm{b}}$ & & 180.0 \\
\hline$x,{ }^{\mathrm{d}} \%$ & $79(11)$ & & 100 & 93 & $21(11)$ & & 7 \\
\hline
\end{tabular}

a The parameters are given in $\AA$ and deg. Threefold standard deviations are in parentheses. Superscript numbers $1,2, \ldots, 9$ indicate groups, in which parameters were refined with fixed differences. The CCSD(T) calculation was performed with cc-pVTZ basis set.

b Fixed parameter, see text for details.

c Dependent parameter.

d Conformational composition. Theoretical values were calculated at $305 \mathrm{~K}$ using the Boltzmann distribution and total energies.

e $r_{\mathrm{e}}$ equilibrium distance between the positions of atomic nuclei corresponding to the minimum of the potential energy.

f $r_{\mathrm{g}}$ average internuclear distance at the temperature of the experiment.

g $r_{\alpha}$ distance between vibrationally averaged positions of atoms, or better: centers of electron densities.

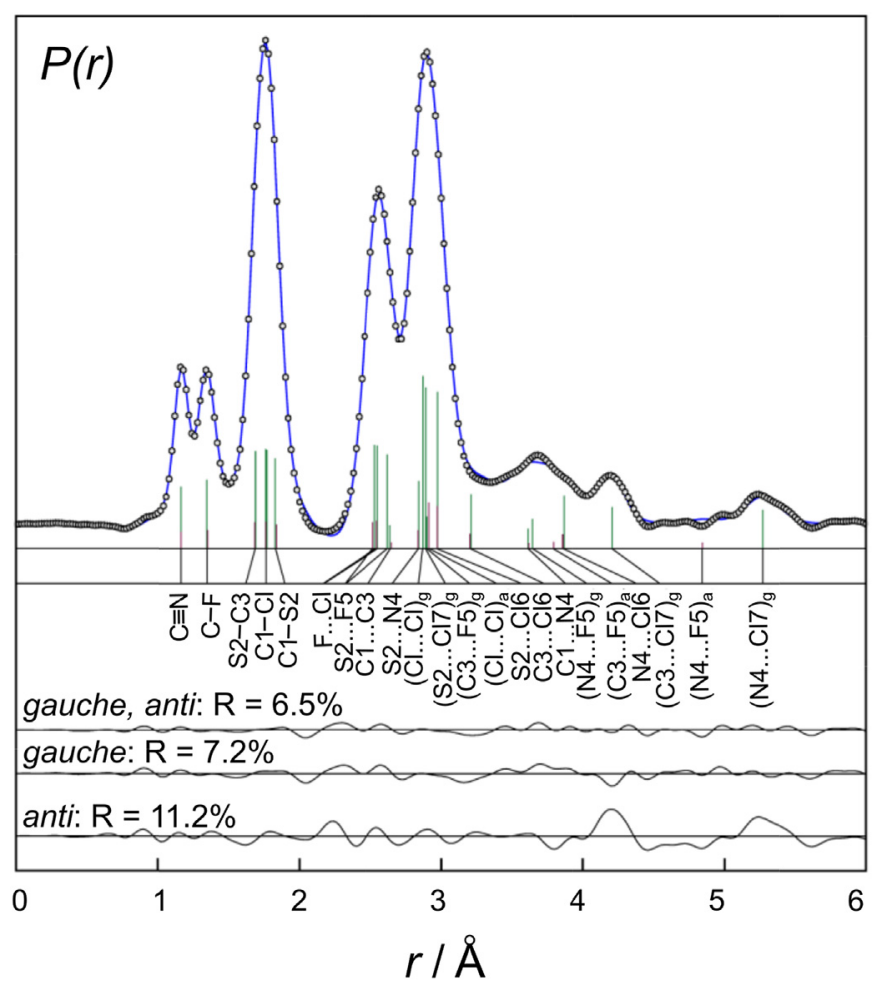

Fig. 3. Experimental (circles) and model (line) radial distribution functions of $\mathrm{CCl}_{2} \mathrm{FSCN}$. The difference curves for the tested models are also given. Subscript letters a and $\mathrm{g}$ indicate terms related only to anti and gauche conformers, correspondingly.

shortening of this bond with respect to the sum of the van der Waals radii of the involved atoms does not enable us to classify this interaction. Nevertheless, its value of $167.5^{\circ}$ for the $\mathrm{N} \cdots \mathrm{Cl}-\mathrm{C}$ angle and the results from the NBO calculations computing an electron donor-acceptor interaction between the nitrogen lone pair and the
Table 4

Comparison of geometrical parameters of different X-SCN compounds in the gas phase.

\begin{tabular}{|c|c|c|c|c|c|}
\hline & $\mathrm{C} \equiv \mathrm{N}$ & $\mathrm{C} 1-\mathrm{S} 2$ & $\mathrm{~S} 2-\mathrm{C} 3$ & $\mathrm{C}-\mathrm{Cl}$ & $\mathrm{C}-\mathrm{S}-\mathrm{C}$ \\
\hline gauche $-\mathrm{CH}_{2} \mathrm{Cl}-\mathrm{SCN}$ & $1.163(3)$ & $1.818(2)$ & $1.698(4)$ & $1.777(2)$ & $99.8(15)$ \\
\hline anti- $\mathrm{CH}_{2} \mathrm{Cl}-\mathrm{SCN}$ & $1.164(3)$ & $1.835(2)$ & $1.698(4)$ & $1.773(2)$ & $96.5(35)$ \\
\hline $\mathrm{CCl}_{3}-\mathrm{SCN}$ & 1.163(9) & $1.839(2)$ & $1.697(13)$ & $1.768(2)^{b}$ & $99.9(17)$ \\
\hline gauche- $\mathrm{CCl}_{2} \mathrm{~F}-\mathrm{SCN}$ & $1.165(5)$ & $1.828(13)$ & $1.690(8)$ & $1.766(4)^{b}$ & $96.5(13)$ \\
\hline anti- $\mathrm{CCl}_{2} \mathrm{~F}-\mathrm{SCN}$ & $1.165(5)$ & $1.839(13)$ & $1.685(8)$ & $1.762(4)$ & $97.0(13)$ \\
\hline
\end{tabular}

a $r_{\mathrm{g}}$ and $<_{\mathrm{e}}$ geometrical parameters in $\AA$ and deg are given, if not otherwise stated, this parameters are defined in Table 3. Error estimates are three times standard deviations in this work. For definition of errors taken from literature see corresponding references.

b Average value.

$\sigma^{*}(\mathrm{Cl}-\mathrm{C})$ orbital, respectively, suggest that this interaction is perhaps a weak halogen contact.

As a consequence of the chalcogen intermolecular interaction previously described, the XRD refinement shows a "T" shaped coordination at the sulfur atom for this compound (Fig. 6). A similar coordination environment for the sulfur atom was reported for $\mathrm{CH}_{2}(\mathrm{SCN})_{2}[23]$.

Chalcogen $\mathrm{N}$...S interactions are also present in dichloromethyl and trichloromethylthiocyanate molecules $[2,3]$. $\mathrm{N} \cdots \mathrm{Cl}$ contacts are interesting to be compared as well. Evidence for this interaction is found in both, $\mathrm{CCl}_{2} \mathrm{FSCN}$ and $\mathrm{CCl}_{3} \mathrm{SCN}$, but not in $\mathrm{CH}_{2} \mathrm{ClSCN}$.

Even though crystalline $\mathrm{CCl}_{2} \mathrm{FSCN}$ does not show $\mathrm{Cl} \cdots \mathrm{S}$ interactions, these intermolecular contacts were detected in the other two thiocyanate species. In $\mathrm{CH}_{2} \mathrm{ClSCN}$ this interaction presents a chalcogen-bond-type behavior, while $\mathrm{CCl}_{3} \mathrm{SCN}$ evidences a $\mathrm{Cl} \cdot$..S halogen contact.

\section{Conclusion}

The crystal structure of $\mathrm{CCl}_{2} \mathrm{FSCN}$ contains solely the gaucheconformer while in the gas phase both gauche- and anti-conformations are present in equilibrium at room temperature, with the 
Table 5

$\mathrm{CF}_{2} \mathrm{ClSCN}$ non-bonding intermolecular interactions characteristics.

\begin{tabular}{|c|c|c|c|c|c|}
\hline Intermolecular contact & Distance $(\AA)$ & Angle (degrees) & Sum of van der Waals radii $(\AA)$ & Shortening $(\AA)$ & Contact type proposed \\
\hline $\mathrm{N}^{\mathrm{a}} \cdots \mathrm{S}-\mathrm{C}(1)^{\mathrm{b}}$ & 3.19 & 159.0 & 3.35 & 0.16 & Chalcogen-bond \\
\hline $\mathrm{N}^{\mathrm{a}} \cdots \mathrm{Cl}-\mathrm{C}(1)^{\mathrm{c}}$ & 3.25 & 167.5 & 3.30 & 0.05 & - \\
\hline
\end{tabular}

${ }^{\mathrm{a}} x, y, z$.

$1 / 2+x, 1 / 2-y, 1-z$

c $3 / 2-x, 1-y, 1 / 2+z$.

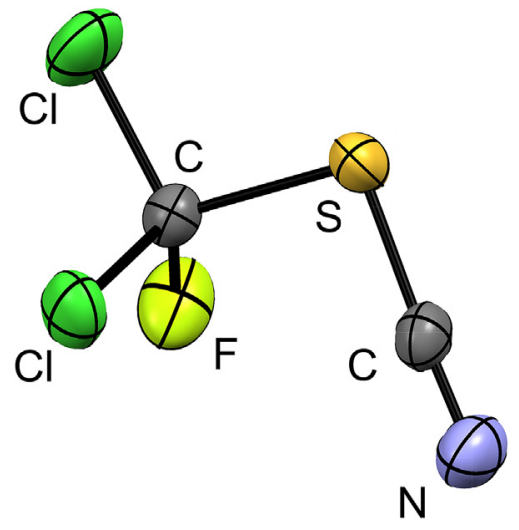

Fig. 4. Molecular structure of $\mathrm{CCl}_{2} \mathrm{FSCN}$ in the crystal determined by X-ray diffraction at $193 \mathrm{~K}$.

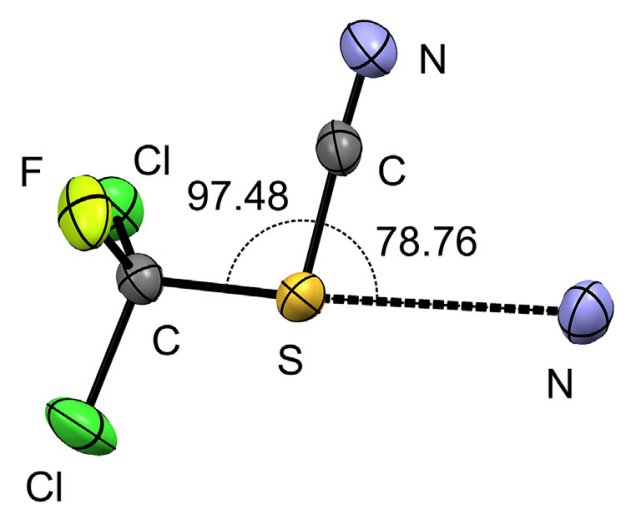

Fig. 6. T-shaped coordination environment of the sulfur atom in $\mathrm{CCl}_{2} \mathrm{FSCN}$. a

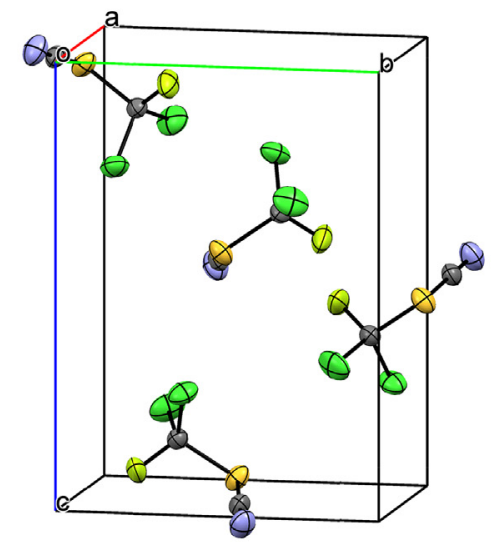

b

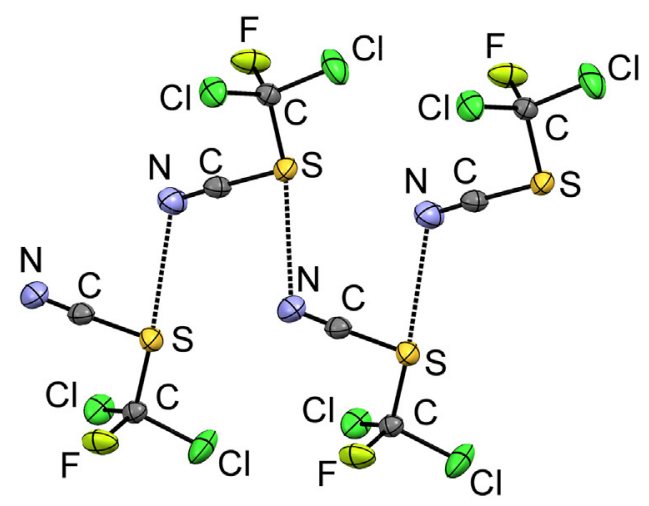

C

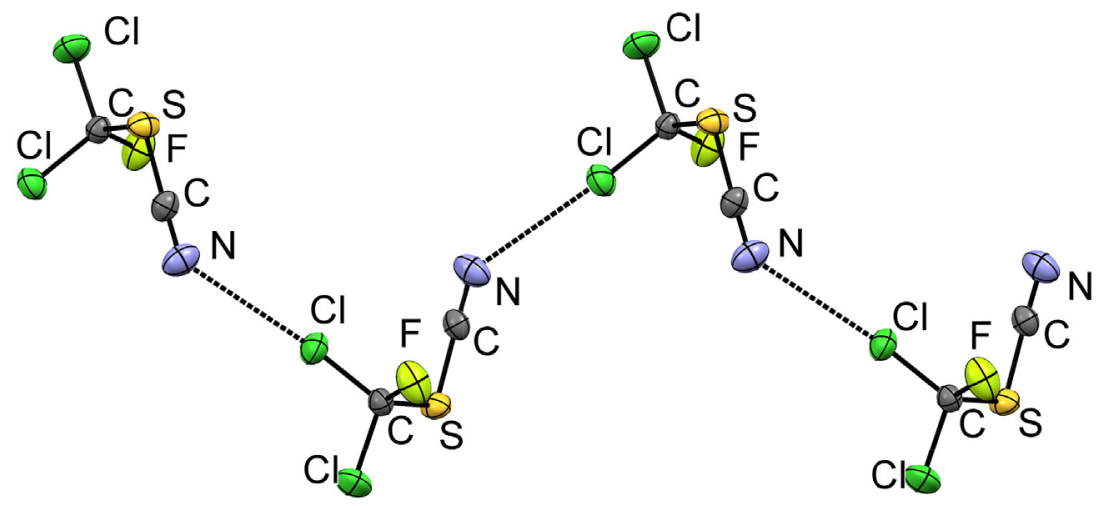

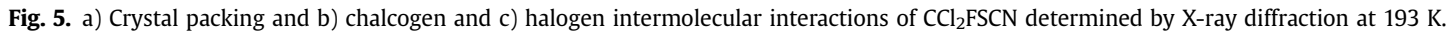


gauche-conformer being the most stable. The parameters of the gauche-structure in both, solid and gas phase, are in good agreement. The $\mathrm{C} \equiv \mathrm{N}$ bond lengths remain almost constant in $\mathrm{CH}_{2} \mathrm{ClSCN}$, $\mathrm{CCl}_{3} \mathrm{SCN}$ and $\mathrm{CCl}_{2} \mathrm{FSCN}$ in the gas phase $\left(r_{\mathrm{e}}=1.160(5), 1.158(9)\right.$, $1.160(5) \AA$ ), but they differ markedly from the solid-state values (1.145(5), 1.144(6), 1.144(9) Å, all 3 e.s.d.s), which themselves as a group are similar. This seeming systematic solid/gas difference finds its explanation in the large anisotropy of valence electron density of the terminal triply-bonded nitrogen atoms and the consequent inability of the electron-density based X-ray diffraction method to represent the nuclear position of nitrogen. The lengths of both $\mathrm{C}-\mathrm{S}$ bonds are also similar in the gas and crystalline phases. The $\mathrm{C}-\mathrm{Cl}$ bond lengths are also very similar within error limits in both gas and solid state, and the same applies for the $\mathrm{C}-\mathrm{F}$ bond lengths. Similarly, the angles found in gas and in solid states resembles. The qualitative relationships between different parameters are the same both in crystal and in gas, despite the fact that data were acquired with a different technique in each phase and the parameters are specifically defined for each case. In the crystal structure several intermolecular interactions, in particular halogenand chalcogen-type interactions, were observed and analyzed by means of the respective structural parameters and by quantumchemical calculations.

\section{Acknowledgment}

The authors thank Deutsche Forschungsgemeinschaft (DFG) for the scholarship of Y. B. M. in Germany and support of the core facility GED@BI (MI 477/21-1), the Alexander von Humboldt-Stiftung (stipend for Y. V. V.), Agencia Nacional de Promoción Científica y Técnica (ANPCYT), Consejo Nacional de Investigaciones Científicas y Técnicas (CONICET), Comisión de Investigaciones de la Provincia de Buenos Aires (CIC), Facultad de Ciencias Exactas, Universidad Nacional de La Plata (UNLP) and Bielefeld University for financial support.

\section{Appendix A. Supplementary data}

Supplementary data related to this article can be found at http:// dx.doi.org/10.1016/j.molstruc.2016.03.097.

\section{Supporting information available}

It contains the molecular electron scattering intensity curves (see Figs. S1-S2), the dependence of the least-squares functional value on the amount of gauche conformation of $\mathrm{CCl}_{2} \mathrm{FSCN}$ (Fig. S3), experimental interatomic distances, mean square amplitudes and vibrational corrections (Tables S1-S2), the dependence of the leastsquares functional value on the amount of gauche-conformation
(Table S3) and experimental Cartesian coordinates of gauche- and anti-conformers in the gas-phase (Tables S4-S5).

\section{References}

[1] E.M. Coyanis, R.E. Rubio, K.I. Gobbato, H.-G. Mack, C.O. Della Védova, J. Mol Struct. 344 (1995) 45-51.

[2] Berrueta Martínez, Y.; Rodríguez Pirani, L. S.; Erben, M. F.; Reuter, C. G.; Vishnevskiy, Y. V.; Stammler, H. G.; Mitzel, N. W.; Della Védova, C. O.; In preparation.

[3] Y. Berrueta Martínez, L.S. Rodríguez Pirani, M.F. Erben, C.G. Reuter Y.V. Vishnevskiy, H.G. Stammler, N.W. Mitzel, C.O. Della Védova, Phys. Chem Chem. Phys. 17 (2015) 15805-15812.

[4] N.N. Yarovenko, S.P. Motornyi, L.I. Kirenskaya, Zh. Obshch. Khim 29 (1959) 3789.

[5] H. Brintzinger, K. Pfannstiel, H. Koddebusch, K.E. Kling, Chem. Ber. 83 (1950) 87-90.

[6] M.J. Frisch, G.W. Trucks, H.B. Schlegel, G.E. Scuseria, M.A. Robb J.R. Cheeseman, J.A. Montgomery Jr., T. Vreven, K.N. Kudin, J.C. Burant, J.M. Millam, S.S. Iyengar, J. Tomasi, V. Barone, B. Mennucci, M. Cossi, G. Scalmani, N. Rega, G.A. Petersson, H. Nakatsuji, M. Hada, M. Ehara, K. Toyota, R. Fukuda, J. Hasegawa, M. Ishida, T. Nakajima, Y. Honda, O. Kitao, H. Nakai, M. Klene, X. Li, J.E. Knox, H.P. Hratchian, J.B. Cross, V. Bakken, C. Adamo, J. Jaramillo, R. Gomperts, R.E. Stratmann, O. Yazyev, A.J. Austin, R. Cammi, C. Pomelli, J.W. Ochterski, P.Y. Ayala, K. Morokuma, G.A. Voth, P. Salvador, J.J. Dannenberg, V.G. Zakrzewski, S. Dapprich, A.D. Daniels, M.C. Strain, O. Farkas, D.K. Malick, A.D. Rabuck, K. Raghavachari, J.B. Foresman, J.V. Ortiz, Q. Cui, A.G. Baboul, S. Clifford, J. Cioslowski, B.B. Stefanov, G. Liu, A. Liashenko, P. Piskorz, I. Komaromi, R.L. Martin, D.J. Fox, T. Keith, M.A. AlLaham, C.Y. Peng, A. Nanayakkara, M. Challacombe, P.M.W. Gill, B. Johnson, W. Chen, M.W. Wong, C. Gonzalez, J.A. Pople, Gaussian 03, Revision C.02 Gaussian, Inc., Wallingford CT, 2004.

[7] Parr, R. G.; Yang, W.; Oxford University Press, New York, USA, 1989.

[8] C. Møller, M.S. Plesset, Phys. Rev. 46 (1934) 618-622.

[9] V.A. Sipachev, J. Mol. Struct. 693 (2004) 235-240.

[10] Sipachev, V. A.; 2001, 567-568, 67-72.

[11] V.A. Sipachev, Struct. Chem. 11 (2000) 167-172.

[12] K. Raghavachari, G.W. Trucks, J.A. Pople, M. Head-Gordon, Chem. Phys. Lett. 157 (1989) 479-483.

[13] M.E. Harding, T. Metzroth, J. Gauss, A.A. Auer, J. Chem. Theory Comput. 4 (2008) 64-74.

[14] J.P. Foster, F. Weinhold, J. Am. Chem. Soc. 102 (1980) 7211-7218.

[15] a) R.J.F. Berger, M. Hoffmann, S.A. Hayes, N.W. Mitzel, Z. Naturforsch 64b (2009) 1259-1268;

b) C.G. Reuter, Yu V. Vishnevskiy, S. Blomeyer, N.W. Mitzel, Z. Naturforsch 71b (2016) 1-13.

[16] Yu V. Vishnevskiy, J. Mol. Struct. 833 (2007) 30-41.

[17] Yu V. Vishnevskiy, J. Mol. Struct. 871 (2007) 24-32.

[18] R. Boese, M. Nussbaumer, in: D.W. Jones, A. Katrusiak (Eds.), Correlations, Transformations, and Interactions in Organic Crystal Chemistry, 7, IUCr Crystallographic Symposia, Oxford, 1994, pp. 20-37.

[19] G.M. Sheldrick, Acta Crystallogr. A 64 (2008) 112-122.

[20] D. Brodalla, D. Mootz, R. Boese, W. Osswald, J. Appl. Crystallogr. 18 (1985) 316-319.

[21] B.J. Lynch, D.G. Truhlar, J. Phys. Chem. A 105 (2001) 2936-2941.

[22] [a] R.G. Gonnade, M.S. Shashidhar, M.M.J. Bhadbhadev, Ind. Inst. Sci. 87 (2007) 149-165;

[b] P. Politzer, J.S. Murray, Chem. Phys. Chem. 14 (2013) 278-294; [c] J.S. Murray, P. Politzer, T. Clark, Phys. Chem. Chem. Phys. 15 (2013) $11178-11189$.

[23] J.H. Konnert, D. Britton, Acta Crystallogr. Sect. B 27 (1971) 781-786. 